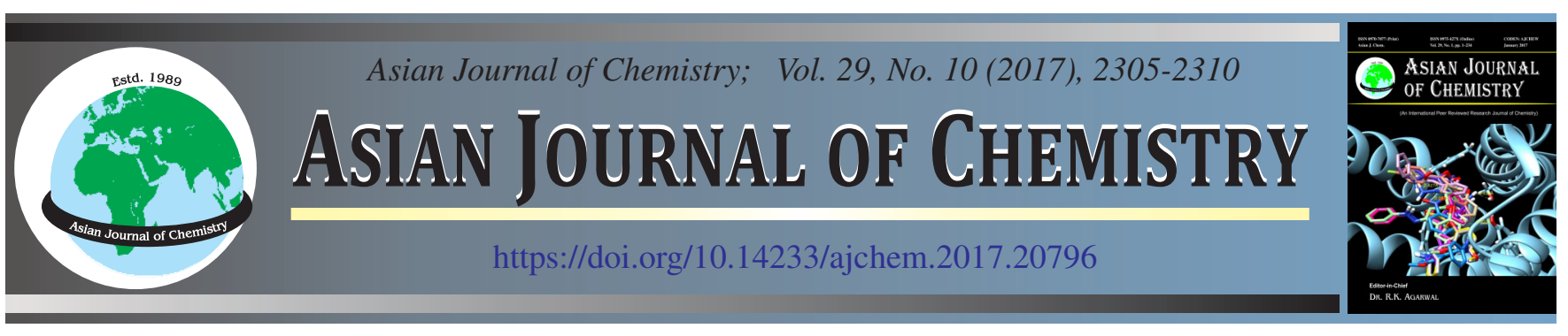

\title{
Rapid, Sensitive and Simple LC-MS/MS Method Development and Validation for Estimation of Phenytoin in Human Plasma
}

\author{
Rampalli Shankar Sheshu* and Palani Shanmugasundaram
}

School of Pharmaceutical Sciences, Vels Institute of Science, Technology \& Advanced Studies, Vels University, Pallavaram, Chennai-600 117, India

*Corresponding author: E-mail: s_seshuqa@yahoo.co.in

\begin{abstract}
Rapid, sensitive and simple LC-MS/MS method was developed and validated for the determination of phenytoin in human plasma with carbamazepine as internal standard. Gradient elution of phenytoin and carbamazepine were achieved at about 3.5 min with total run time 6 min using Intrada-WP RP, $\mathrm{C}_{18}, 150 \times 3 \mathrm{~mm}, 3 \mu$ column. The analyte and internal standard were eluted with the gradient flow profile of B: 2 to $45 \%$ ( 0 to $1 \mathrm{~min}$ ), 45 to $80 \%$ (1 to $4 \mathrm{~min}$ ), 80 to $2 \%$ (4 to $5 \mathrm{~min}$ ). The flow rate was linear from 0 to $5 \mathrm{~mL} / \mathrm{min}$ up to $5 \mathrm{~min}$ and stop at $6 \mathrm{~min}$ and the column oven temperature was $50 \pm 5{ }^{\circ} \mathrm{C}$. Selectivity and sensitivity of the developed method was improved by selecting electron spray ionization technique in +ve ion mode. The standard plots were observed that the linear within the concentration range of $20.176-15016.936 \mathrm{ng} / \mathrm{mL}$ with correlation coefficient $\geq 0.9976$. All the validation parameters were within the acceptable limits.

Keywords: Phenytoin, LC-MS/MS, Chromatography, Electron spray ionization technique.
\end{abstract}

\section{INTRODUCTION}

Phenytoin, chemically is 5,5-diphenylimidazolidine-2,4dione (Fig. 1), belongs to the category of anti-epileptics also known as anticonvulsants is mainly effective in controlling seizures by decelerating impulses in the brain that are responsible for the occurrence of seizures. Phenytoin, a drug with small therapeutic index and the therapeutic concentration range in blood serum will be ranging from 10-20 mg/L [1] for adults. By the intake of $>20 \mathrm{mg} / \mathrm{kg}$ in humans (normal oral adult dose is $6 \mathrm{mg} / \mathrm{kg}$ ) [1] regularly leads to clinical toxicity [2]. The intake of phenytoin might prominently lead to dose-related toxicity due to its complex pharmacokinetics. The factors that emphasize the prominence of therapeutic drug monitoring (TDM) comprises of narrow therapeutic index, associated with the large inter-individual inconsistency of metabolism (half life $16-60 \mathrm{~h}$, depending on plasma levels $[3,4]$ ) and non-linear pharmacokinetics of phenytoin $[5,6]$. In contrast, comparatively few reports have been able to reveal the precedence of therapeutic drug of anti-convulsive drugs [7]. However, therapeutic monitoring of phenytoin using Bayesian forecasting was effectively implemented in order to swiftly attain therapeutic plasma concentrations, using an easy-to-apply phenytoin loading dose regimen in a hospice [8].

The traditional analytical methods which were available have been devised without mass spectrometry detection. Thus,

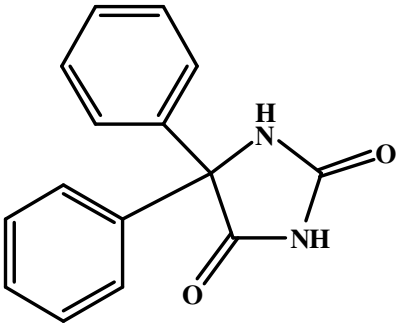

(A)<smiles>NC(=O)N1c2ccccc2C=Cc2ccccc21</smiles>

(B)
Fig. 1. Chemical structure of (A) Phenytoin (B) Carbamazepine

they could not accomplish the entailed sensitivity which was required to quantify the free fraction and low biological concentrations of phenytoin [9]. For authorities such as the Food and Drug Administration (FDA), a validated method is a requisite in order to execute a clinical trial. The advanced analytical chemistry technique that amalgamates liquid chromatography (LC) with MS is highly efficient and specific to independently analyze parent phenytoin and its metabolites [10]. However, the methods included in current publications are imprecise, vulnerable to recognize and measure the anticipated small concentrations of phenytoin in human plasma samples. Furthermore, the large sample volume used in literature is immense for the normal sampling in patients, with a $2 \mathrm{~mL} / \mathrm{min}$ ow rate and thus inappropriate for therapeutic drug [11]. 
The premium objective of the current analytical work was to ascertain a rapid, sensitive and simple LC-MS/MS method that enables to determine phenytoin in human plasma samples. The developed analytical method should incorporate a therapeutic range of free phenytoin concentration ranging from $20.176-15016.936 \mathrm{ng} / \mathrm{mL}$. The propriety of the analytical LCMS method has to be established by validating according to International Organization for Standardization (ISO) 17025 to be used in corresponding investigations with samples which are collected from the patients during clinical trials. The resulting analytical method serves as a prerequisite for further pharmacokinetic studies.

\section{EXPERIMENTAL}

Phenytoin was a gift sample from Anglo French Drugs and Industries Ltd., Bangalore, India. Carbamazepine was obtained from INTAS Pharmaceuticals, Ahmedabad, India. Acetonitrile, tertiary butyl methyl ether and formic acid were procured from Merck Specialities Pvt. Ltd., Mumbai, India.

Standard solutions: Phenytoin and carbamazepine stock solutions of $1 \mathrm{mg} / \mathrm{mL}$ were arranged in acetonitrile, separately. The solutions of phenytoin and carbamazepine at different concentrations were prepared from the above stocks by using water/acetonitrile (50:50 \% v/v) mixture as a diluting fluid.

Processing of plasma samples: Initially, $100 \mu \mathrm{L}$ of accurately measured plasma sample (blank/spiked with analyte) was transferred into $2.5 \mathrm{~mL}$ eppendorf tube containing $50 \mu \mathrm{L}$ of carbamazepine $(5 \mathrm{ng} / \mathrm{mL})$ solution. Next, $50 \mu \mathrm{L}$ of extraction buffer ( $5 \mathrm{mM}$ ammonium formate aqueous solution) was added to the above mixture and swirled for $5 \mathrm{~s}$ on vortex mixer (CM 101, REMI Instruments, Vasai, India). Further, $1.8 \mathrm{~mL}$ of methyl tertiary butyl ether was added as extraction solution and swirled for $10 \mathrm{~min}$. Then it was centrifuged at $5000 \mathrm{rpm}$ maintained at $4{ }^{\circ} \mathrm{C}$. The supernatant was evaporated under nitrogen and reconstituted with $150 \mu \mathrm{L}$ of water: acetonitrile (50:50\% v/v) solution. The final reconstituted samples were injected onto LC-MS/MS.

Chromatographic and mass spectrometry systems and conditions: The current analytical study was performed with 2695 high performance liquid chromatography separation module attached with Quattro Premier XE LC-MS/MS consisted of an electron spray ionization interface was operated by using Software Mass Lynx V 4.1. The analytical column was reverse phase $\mathrm{C} 18$ column (Intrada-WP RP $150 \mathrm{~mm} \times 3.0 \mathrm{~mm}$, $5 \mu$ ) with total analysis run time of $6 \mathrm{~min}$.

Mobile phase A and B were arranged by combining $0.1 \%$ formic acid in the mixture of water and acetonitrile (95:5 v/v and $5: 95 \mathrm{v} / \mathrm{v}$, respectively). The autosampler temperature was $5 \pm 3{ }^{\circ} \mathrm{C}$. The retention time for both analyte and ISTD was close to $3.5 \mathrm{~min}$ with the total run time of $6 \mathrm{~min}$. The gradient program is provided in Table-1. Determination was carried out using multiple reaction monitoring (MRM). Mass spectra detection was performed in the positive ESI mode on API 4000 tandem mass spectrometer. Source parameters and compound parameters were optimized during the infusion of aqueous solution of phenytoin and carbamazepine through the interface connected with the LC. The mass spectrometer conditions were represented in Table-2.

TABLE-1

GRADIENT PROGRAM FOR PHENYTOIN QUANTIFICATION

\begin{tabular}{cccc}
\hline Time & $\begin{array}{c}\text { Mobile } \\
\text { phase A }(\%)\end{array}$ & $\begin{array}{c}\text { Mobile } \\
\text { phase B }(\%)\end{array}$ & $\begin{array}{c}\text { Flow rate } \\
(\mathrm{mL} / \mathrm{min})\end{array}$ \\
\hline 0.01 & 98 & 2 & 0.01 \\
0.50 & 98 & 2 & 0.50 \\
1.00 & 55 & 45 & 1.00 \\
2.00 & 20 & 80 & 2.00 \\
4.00 & 20 & 80 & 4.00 \\
4.50 & 98 & 2 & 4.50 \\
5.00 & 98 & 2 & 5.00 \\
6.00 & & Stop & \\
\hline
\end{tabular}

Validation: Validation was performed according to guidelines of US FDA bioanalytical method validation [12], to determine suitability of the developed LC-MS/MS method for the quantification of phenytoin in human plasma. The specificity was carried out by testing human plasma from six different lots. Each blank plasma sample was assessed for interference with established extraction procedure and compared with unextracted plasma samples of the phenytoin of concentration corresponding to the LLOQ.

The specificity of the developed analytical method was assessed by injecting standard blank human plasma from ten different lots. Out of ten, seven lots were of intended anticoagulant $\left(\mathrm{K}_{2}\right.$ EDTA) plasma, one haemolytic plasma, one lipidemic plasma and one lot containing heparin as anticoagulant.

\begin{tabular}{|c|c|c|c|c|c|c|}
\hline \multicolumn{7}{|c|}{$\begin{array}{c}\text { TABLE-2 } \\
\text { MASS SPECTROMETER CONDITIONS }\end{array}$} \\
\hline Compound name & Ions monitored & $\begin{array}{l}\text { Dwell time } \\
(\mathrm{ms})\end{array}$ & $\begin{array}{c}\text { Declustering } \\
\text { potential (DP) }\end{array}$ & $\begin{array}{l}\text { Collision energy } \\
\text { (CE) }\end{array}$ & $\begin{array}{l}\text { Collision cell exit } \\
\text { potential (CXP) }\end{array}$ & $\begin{array}{c}\text { Entrance } \\
\text { potential (CXP) }\end{array}$ \\
\hline Phenytoin & $253.02 \rightarrow 82.0 \& 104.0$ & 100 & 51 & 49 & 6 & 10 \\
\hline Carbamazepine & $237.1 \rightarrow 194.0$ & 100 & 58 & 29 & 13 & 10 \\
\hline \multicolumn{3}{|l|}{ Mode of operation } & \multicolumn{4}{|c|}{ Electron spray ionization (positive ion mode) } \\
\hline \multicolumn{3}{|c|}{ Collision activated dissociation (CAD) } & \multicolumn{4}{|c|}{10} \\
\hline \multicolumn{3}{|c|}{ Curtain gas (CUR) } & \multicolumn{4}{|l|}{25} \\
\hline \multicolumn{3}{|c|}{ Ion source gas 1 (Gas 1$)$} & \multicolumn{4}{|l|}{40} \\
\hline \multicolumn{3}{|c|}{ Ion source gas 2 (Gas 2$)$} & \multicolumn{4}{|l|}{50} \\
\hline \multicolumn{3}{|c|}{ Ion spray voltage (IS) } & \multicolumn{4}{|l|}{5500} \\
\hline \multicolumn{3}{|l|}{ Temperature $\left({ }^{\circ} \mathrm{C}\right)$} & \multicolumn{4}{|l|}{450} \\
\hline \multicolumn{3}{|l|}{ Pause time (ms) } & \multicolumn{4}{|c|}{5} \\
\hline \multicolumn{3}{|l|}{ Collision gas } & \multicolumn{4}{|l|}{ Nitrogen } \\
\hline
\end{tabular}


The matrix effect of the developed method was determined by injecting plain human plasma from six different lots which were chromatographically screened. With each lot of plasma, Concentration equivalent to HQC and LQC were prepared in triplicates at each level from each lot and \% CV of back calculated concentrations for both level of quality control samples were calculated.

A $1 / x 2$ weighted least square regression analysis was adopted to establish linearity of the method. The constructed linear plots were coupled with a 10 point standard curve. The established plots were found to be linear within the range of 20.176-15016.936 ng/mL.

The precision of the developed method was assessed by investigating quality control samples at different concentration levels corresponding to lower limit of quantification (LLOQ), lower quality control (LQC), Medium quality control 1 (MQC1), medium quality control 2 (MQC2) and higher quality control (HQC) for the duration of line of validation. Each level of quality control samples were investigated six replicates. It was evaluated by the calculating $\% \mathrm{CV}$ at different levels of quality control samples.

Within and between batches accuracy was calculated as the absolute value of the ratio of the calculated mean values of the quality control samples to their respective nominal values and expressed as percentage.

The recoveries for analyte and internal standard ware assessed by computing the ratio of areas from quality control samples of extracted against unextracted plasma samples at HQC, MQC1, MQC2 and LQC levels. The dilution integrity of the developed method was confirmed by preparing the dilution integrity quality control sample, which is around 2.5 fold than HQC. The DIQC sample is further diluted by $1 / 5$ and $1 / 10$ times.

The ruggedness of the developed method was assessed by analyzing previously passed precission and accuracy batch with different column and different analyst. Reinjection reproducibility was performed by injecting the formerly accepted $\mathrm{P}$ and $\mathrm{A}$ batch following a time of $39 \mathrm{~h}$ and $49 \mathrm{~min}$ stored at 5 $\pm 3{ }^{\circ} \mathrm{C}$.

The stability of analyte and internal standard was analyzed in plasma to describe the each operation. i.e. freeze and thaw stability, bench top stability, autosampler stability, wet extract stability at room temperature and at refrigerated temperature and dry extract stability were carried out. All stability studies parameters were carried out in different testing conditions with LQC and HQC each at six replicates. Testing conditions for the stability study are summarized in Table-3.

\section{RESULTS AND DISCUSSION}

System suitability of the developed method was carried out at the beginning of the method validation and on every day as a primary test. The $\% \mathrm{CV}$ for the retention times and peak area ratio (analyte area/internal standard area) were found to be $\leq 0.42$ and $\leq 0.44$; and $\leq 3.25$ for the analyte and ISTD, respectively. All the examined plasma samples from different lots were showed negligible interference at the retention time of analyte (area of the peak at the retention time of analyte in the standard blank samples was $\leq 20.00 \%$ of the area of the analyte in the extracted LLOQ sample) and internal standard (i.e. and it was $\leq 5.00 \%$ for the internal standard). For the preparation of calibration curves and quality control samples pooled plasma were used as a blank matrix. The resulting chromatograms of standard blank and LLOQ standard with pooled plasma are represented in Fig. 2. Sensitivity of the LCMS/MS method was determined at LLOQ level. The \% CV and $\%$ mean accuracy for analyte at LLOQ level were found to be 3.19 and 106.87 , respectively.

The calibration plots constructed during the line of validation were observed linear for the regular concentration range of $20.176-15016.936 \mathrm{ng} / \mathrm{mL}$ with the correlation coefficient (r) $\geq 0.9976$. The $\%$ mean accuracy and $\% \mathrm{CV}$ for the calibration curve standards were ranged from 93.75-105.87 and 0.714.05 , respectively

The observed chromatograms throughout the line of validation was satisfactory and corresponding chromatograms of standard blank and LLOQ standard are shown in Fig. 2.

Within/between batch precision and accuracy was evaluated by examining 3 sets of calibration curves and five levels of QC samples. Each set of calibration curve consists of 6 replicates of the each QC level namely, LLOQQC, LQC, M1QC, M2QC and HQC. The results were represented in Table- 4 . The $\% \mathrm{CV}$ within/between batch precision and accuracy was less than $15 \%$ for all QC samples except LLOQQC and it was less than $20 \%$ for LLOQQC.

The $\%$ mean recovery for phenytoin was assessed by calculating the area ratios of the extracted against unextracted plasma quality control samples at HQC, MQC1, MQC2 and LQC levels. The \% mean recovery for phenytoin at HQC, MQC1, MQC2 and LQC levels were observed as 94.93, 100.24, 87.06 and $92.60 \%$, respectively. Over all \% mean recovery and \% CV at all QC levels was 93.710 and 5.83, respectively. The overall $\%$ mean recovery for internal standard was found to be 95.28. The dilution integrity was assessed by diluted the stock solution of phenytoin to $12575.516 \mathrm{ng} / \mathrm{mL}$

TABLE-3

STABILITY STUDY CONDITIONS AND \% MEAN STABILITY RESULTS

\begin{tabular}{|c|c|c|c|c|}
\hline \multirow{2}{*}{ Stability study } & \multirow{2}{*}{ Condition } & \multirow{2}{*}{$\mathrm{N}$} & \multicolumn{2}{|c|}{ Mean stability (\%) } \\
\hline & & & HQC & LQC \\
\hline Freeze thaw stability (number of cycles 4 ) & Four freeze thaw stored at $-28 \pm 5^{\circ} \mathrm{C}$ & \multirow{8}{*}{6} & 89.00 & 90.29 \\
\hline Bench top stability & $6 \mathrm{~h} 22 \mathrm{~min}$ storage at room temperature & & 95.47 & 99.77 \\
\hline Wet extract stability at room temperature & $4 \mathrm{~h} 31 \mathrm{~min}$ at room temperature & & 94.55 & 97.42 \\
\hline Wet extract stability at refrigerated temperature & $5 \mathrm{~h} 20 \mathrm{~min}$ storage at $2-8^{\circ} \mathrm{C}$ & & 94.70 & 98.52 \\
\hline Dry extract stability & Storage at $-20 \pm 5^{\circ} \mathrm{C}$ for a period of $70 \mathrm{~h} 42 \mathrm{~min}$ & & 91.66 & 96.38 \\
\hline Auto sampler stability & Storage for $73 \mathrm{~h} 8 \mathrm{~min}$ at $5 \pm 3^{\circ} \mathrm{C}$ & & 98.96 & 101.5 \\
\hline Stability of analyte in blood at room temperature & Storage at room temperature for $4 \mathrm{~h} 13 \mathrm{~min}$ & & 97.25 & 94.38 \\
\hline Stability of analyte in blood at refrigerated & Storage at $2-8^{\circ} \mathrm{C}$ for $3 \mathrm{~h} 14 \mathrm{~min}$ & & 97.41 & 96.94 \\
\hline
\end{tabular}



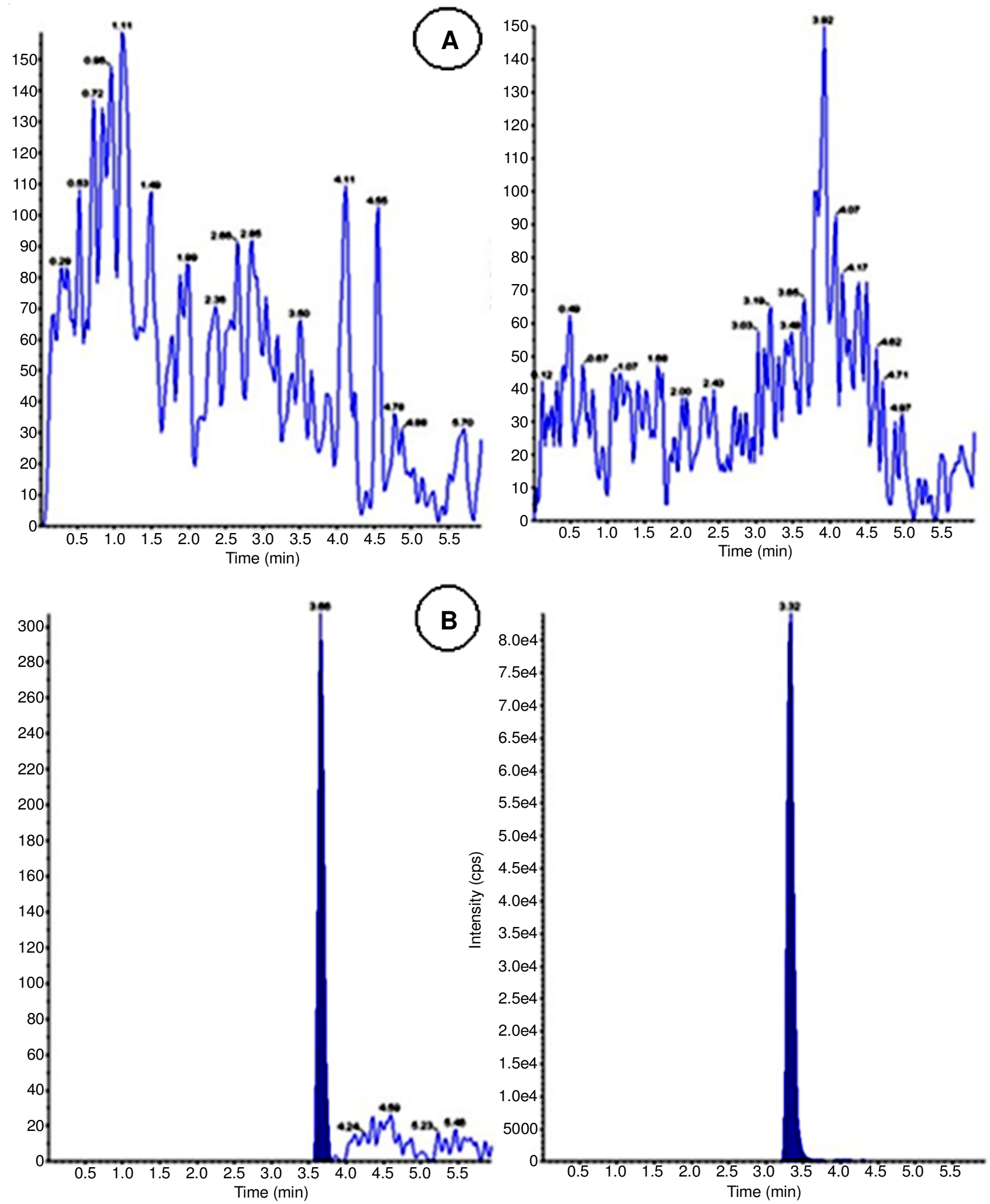

Fig. 2. Representative chromatograms of (A) Standard blank (B) LLOQ standard

in tested plasma. The $\mathrm{P}$ and $\mathrm{A}$ for dilution integrity standards at 1 in 5 and 1 in 10 dilution were assessed by measuring the samples against calibration curve standards. The precision and $\%$ mean accuracy for dilution integrity of $1 / 5$ and $1 / 10$ for phenytoin were observed as $6.18,1.87 \%$ and $94.83,96.72$ (which were within acceptance limit 85.00-115.00\%), respectively.
Ruggedness was performed by analyzing previously passed $\mathrm{P}$ and $\mathrm{A}$ batch with different column and different analyst. The results from quality control samples are presented in Table-5.

Reinjection reproducibility was achieved by injecting the formerly accepted precision and accuracy batch following a period of $39 \mathrm{~h}$ and $49 \mathrm{~min}$ stored at $5 \pm 3{ }^{\circ} \mathrm{C}$. The $\% \mathrm{CV}$ and $\%$ 


\begin{tabular}{|c|c|c|c|c|}
\hline \multicolumn{5}{|c|}{$\begin{array}{c}\text { TABLE-4 } \\
\text { WITHIN/BETWEEN BATCH PRECISION } \\
\text { AND ACCURACY DATA }\end{array}$} \\
\hline Sample & $\mathrm{n}$ & $\begin{array}{l}\text { Mean conc. found } \pm \\
\mathrm{SD}(\mathrm{ng} / \mathrm{mL})\end{array}$ & $\mathrm{CV}(\%)$ & $\begin{array}{c}\text { Mean } \\
\text { accuracy }(\%)\end{array}$ \\
\hline LLOQ & 6 & $23.383 \pm 2.595$ & 11.10 & 113.19 \\
\hline LQC & 6 & $64.4410 \pm 4.632$ & 7.19 & 106.69 \\
\hline MQC 1 & 6 & $6183.785 \pm 163.511$ & 2.64 & 94.19 \\
\hline MQC 2 & 6 & $1249.254 \pm 34.764$ & 2.78 & 95.14 \\
\hline HQC & 6 & $11321.322 \pm 546.483$ & 4.83 & 93.12 \\
\hline \multicolumn{5}{|c|}{ Day I (Batch-II) within batch precision and accuracy } \\
\hline LLOQ & 6 & $21.341 \pm 0.947$ & 4.44 & 103.31 \\
\hline LQC & 6 & $55.431 \pm 1.077$ & 1.94 & 91.77 \\
\hline MQC 1 & 6 & $5801.885 \pm 177.179$ & 3.05 & 88.37 \\
\hline MQC 2 & 6 & $1163.079 \pm 34.63$ & 2.98 & 88.58 \\
\hline HQC & 6 & $10884.174 \pm 290.151$ & 2.67 & 89.52 \\
\hline \multicolumn{5}{|c|}{ Day II (Batch-III) within batch precision and accuracy } \\
\hline LLOQ & 6 & $22.368 \pm 1.8144$ & 8.11 & 108.28 \\
\hline LQC & 6 & $59.298 \pm 0.6355$ & 1.07 & 98.17 \\
\hline MQC 1 & 6 & $6484.4855 \pm 115.981$ & 1.79 & 98.77 \\
\hline MQC 2 & 6 & $1282.389 \pm 18.900$ & 1.47 & 97.66 \\
\hline HQC & 6 & $12325.733 \pm 212.662$ & 1.73 & 101.38 \\
\hline \multicolumn{5}{|c|}{ Between batch precision and accuracy } \\
\hline Q & 18 & $22.3643 \pm 0.824$ & 3.69 & 108.26 \\
\hline LQC & 18 & $59.723 \pm 2.191$ & 3.67 & 98.88 \\
\hline MQC 1 & 18 & $6156.718 \pm 32.122$ & 0.52 & 93.77 \\
\hline MQC 2 & 18 & $1231.574 \pm 9.122$ & 0.74 & 93.79 \\
\hline $\mathrm{HQC}$ & 18 & $11510.409 \pm 174.713$ & 1.52 & 94.67 \\
\hline
\end{tabular}

mean accuracy of back calculated concentrations for HQC, MQC1, MQC2 and LQC levels were ranging from 2.06 to 2.98 and 94.72 to 97.88 , respectively. The $\% \mathrm{CV}$ and $\%$ mean accuracy of back calculated concentrations for LLOQ QC were observed as 8.66 and 98.91 , respectively. The results were represented in Table-6.

\begin{tabular}{lcccc}
\multicolumn{5}{c}{ TABLE-6 } \\
\multicolumn{5}{c}{$\begin{array}{c}\text { PRE-INJECTION REPRODUCIBILITY } \\
\text { PRECISION AND ACCURACY }\end{array}$} \\
\hline Sample & $\mathrm{n}$ & $\begin{array}{c}\text { Mean conc. } \\
\text { found } \pm \text { SD }(\mathrm{ng} / \mathrm{mL})\end{array}$ & $\begin{array}{c}\text { CV } \\
(\%)\end{array}$ & $\begin{array}{c}\text { Mean } \\
\text { accuracy }(\%)\end{array}$ \\
\hline LLOQ & 6 & $21.0607 \pm 1.540$ & 7.31 & 101.95 \\
LQC & 6 & $60.598 \pm 1.617$ & 2.67 & 100.33 \\
MQC 1 & 6 & $6401.624 \pm 115.043$ & 1.80 & 97.50 \\
MQC 2 & 6 & $1272.378 \pm 17.544$ & 1.38 & 96.90 \\
HQC & 6 & $11635.187 \pm 146.764$ & 1.26 & 95.70 \\
\hline
\end{tabular}

Stability of analyte and internal standard: Long term stock solution stability for the analyte and internal standard at concentration 1006041.260 and $106217.034 \mathrm{ng} / \mathrm{mL}$, respectively was assessed with aqueous standards following a period of 24 days $21 \mathrm{~h} 00 \mathrm{~min}$ at $2-8{ }^{\circ} \mathrm{C}$. Stability was evaluated by compared against the freshly weighed stock concentration of analyte $(1001591.684 \mathrm{ng} / \mathrm{mL})$ and internal standard $(107229.936$ $\mathrm{ng} / \mathrm{mL}$ ) and prepared aqueous standard equivalent to SS HQC concentration of $200318.337 \mathrm{ng} / \mathrm{mL}$ and internal standard dilution concentration of $536.150 \mathrm{ng} / \mathrm{mL}$ injected the stability $(\mathrm{n}=6)$ and comparison samples $(\mathrm{n}=6)$ from the similar vial. The $\%$ mean stability of analyte and internal standard was observed as 100.32 and 98.74 , respectively.

Stability experiments in blood/plasma were carried out in different settings $(\mathrm{n}=6)$ of $\mathrm{LQC}$ and $\mathrm{HQC}$ samples (Table-3) and the stability was assessed in each study under various conditions by contrast them against the newly arranged calibration standards and quality control samples. Freeze and thaw stability of the quality control samples was assessed after 4 freeze thaw cycles stored at $-28 \pm 5^{\circ} \mathrm{C}$. Bench top stability of the quality control samples was determined for a period of $6 \mathrm{~h}$ and $22 \mathrm{~min}$ stored at room temperature. Autosampler stability of the processed quality control samples was determined for a period of $73 \mathrm{~h}$ and $8 \mathrm{~min}$ at $5 \pm 3{ }^{\circ} \mathrm{C}$. Wet extract stability of quality control samples was determined for a period of $4 \mathrm{~h}$ and $31 \mathrm{~min}$ by storing them at room temperature. And this stability study also conducted for a period of $5 \mathrm{~h}$ and $20 \mathrm{~min}$ by storing them at $5 \pm 3{ }^{\circ} \mathrm{C}$. Dry extract stability of the spiked quality control samples was determined for a period of $70 \mathrm{~h}$ and $42 \mathrm{~min}$ by storing them at -20 $\pm 5{ }^{\circ} \mathrm{C}$. Stability of analyte in blood was determined at room temperature for a period of $4 \mathrm{~h}$ and $13 \mathrm{~min}$. This study also performed for analyte at refrigerated temperature $\left(5 \pm 3{ }^{\circ} \mathrm{C}\right)$ for a period of $3 \mathrm{~h} 14 \mathrm{~min}$.

The \% mean stability of analyte for HQC and LQC from all the stability parameters was found to be within the acceptance limit of $85.00-115.00 \%$. The stability data for all the parameters at various conditions are represented in Table- 3 .

\section{Conclusion}

In conclusion, the method was developed and validated for the quantitation of phenytoin in stabilized human plasma over the concentration range of $20.176-15016.936 \mathrm{ng} / \mathrm{mL}$ using carbamazepam as internal standard. The precision and mean accuracy are within the acceptable limits. Constant recoveries were practical for $\mathrm{LQC}, \mathrm{MQC} 2, \mathrm{MQC} 1$ and $\mathrm{HQC}$. The method is precise and accurate to dilute the samples, if needed. The stability tests were carried out throughout the line of validation reveals that the phenytoin was stable at different settings in plasma/blood samples. Finally, the method was also proved to be rugged by different column and different analyst.

TABLE-5

RUGGEDNESS PRECISION AND ACCURACY

\begin{tabular}{lccc|ccc}
\hline \multirow{2}{*}{ Sample } & \multicolumn{3}{c|}{ Different column } & \multicolumn{3}{c}{ Different analyst } \\
\cline { 2 - 8 } & $\begin{array}{c}\text { Mean conc. found } \pm \text { SD } \\
(\mathrm{ng} / \mathrm{mL})(\mathrm{n}=6)\end{array}$ & $\mathrm{CV}(\%)$ & Mean accuracy $(\%)$ & $\begin{array}{c}\text { Mean conc. found } \pm \text { SD } \\
(\mathrm{ng} / \mathrm{mL})(\mathrm{n}=6)\end{array}$ & $\mathrm{CV}(\%)$ & Mean accuracy $(\%)$ \\
\hline LLOQ & $19.330 \pm 0.947$ & 4.90 & 93.57 & $18.398 \pm 2.26$ & 12.3 & 89.06 \\
LQC & $59.876 \pm 0.481$ & 0.8 & 99.13 & $57.364 \pm 4.242$ & 7.4 & 94.97 \\
MQC 1 & $6359.788 \pm 42.343$ & 0.67 & 96.87 & $6501.446 \pm 402.534$ & 6.19 & 99.12 \\
MQC 2 & $1255.2673 \pm 15.484$ & 1.23 & 95.60 & $1307.6692 \pm 84.873$ & 6.49 & 99.59 \\
HQC & $11587.294 \pm 78.266$ & 0.68 & 95.30 & $12089.1965 \pm 732.966$ & 6.06 & 99.43 \\
\hline
\end{tabular}




\section{REFERENCES}

1. E.W. Evens, M. Oellerich and D.W. Holt, Drug Monitoring, Leitfaden fur die klinische Praxis, Abbott, Wiesbaden, edn 2, pp. 60-63 (1994).

2. Poisindex summary: Phenytoin, Thomson Reuters, MICROMEDEX, Greenwood Village,CO.http://www.thomsonhc.com/hcs/librarian/ ND_T/HCS/ND_PR/Main/CS/C686E6/DUPLICATIONSHIELD SYNC/89B08F/ND_PG/PRIH/ND_B/CS/SB K/2/ND_P/Main/ PFActionId/hcs.common.RetrieveDocumentCommon/DocId/105/ ContentSetId/68/SearchTerm/phenytoin/SearchOption/BeginWith.

3. B. von W. Forth, D. Henschler and W. Rummel, Allgemeine und Spezielle Pharmakologie und Toxikologie, BI-Wiss.-Verl., Mannheim, Elsevier, edn 6 (2004).

4. U. Schaefer, S. Leisi, P. Höchner, R. Andenmatten, M. Lagler and Ch. Elene, Arzneimittel-Kompendium der Schweiz, Documed AG, Basel, edn 32, p. 3905 (2011)

5. E. Martin, T.N. Tozer, L.B. Sheiner and S. Riegelman, J. Pharmacokinet. Pharmacodyn., 5, 579 (1977);

https://doi.org/10.1007/BF01059685.
6. C. Queckenberg and U. Fuhr, Eur. J. Clin. Pharmacol., 65, 109 (2009); https://doi.org/10.1007/s00228-008-0579-2.

7. T. Tomson, M.L. Dahl and E. Kimland, Cochrane Database Syst. Rev., CD002216 (2007); https://doi.org/10.1002/14651858.CD002216.

8. E.F. Martinelli and S.F. Mühlebach, J. Clin. Pharm. Ther, 28, 385 (2003); https://doi.org/10.1046/j.0269-4727.2003.00506.x.

9. M. Burt, D.C. Anderson, J. Kloss and F.S. Apple, Clin. Chem., 46, 1132 (2000).

10. M.H. Nelson, A.K. Birnbaum, P.J. Nyhus and R.P. Remmel, J. Pharm. Biomed. Anal., 17, 1311 (1998); https://doi.org/10.1016/S0731-7085(98)00018-1.

11. B. Rambeck, U.H. Jürgens, T.W. May, H. Wolfgang Pannek, F. Behne, A. Ebner, A. Gorji, H. Straub, E.J. Speckmann, B. Pohlmann-Eden and W. Löscher, Epilepsia, 47, 681 (2006); https://doi.org/10.1111/j.1528-1167.2006.00504.x.

12. L.R. Synder, J.J. Kirland and J.L. Glajch, Practical HPLC Method Development, Wiley, edn 2, (2003). 